\title{
ADIÇÃO DE PALHA DE MILHETO AO SOLO PARA REDUÇÃO DA PODRIDÃO DO COLO EM FEIJOEIRO ${ }^{1}$
}

\author{
João Vicente Pereira Neto², Luiz Eduardo Bassay Blum²
}

\begin{abstract}
ADDITION OF PEARL MILLET STRAW TO SOIL FOR REDUCTION OF SOUTHERN BLIGHT IN COMMOM BEAN

Many plants, such as pearl millet (Pennisetum glaucum), have been cultivated with the purpose of covering or being incorporated to soil. This practice might improve soil chemical, physical and biological characteristics. These changes in soil features can affect diseases, especially those caused by soilborne pathogens, such as Sclerotium rolfsii. In this study, a group of experiments was conducted in a randomized block design to evaluated the effects of pearl millet straw addition $(\mathrm{N}=0.8 \%$; $\mathrm{P}=0.14 \% ; \mathrm{K}=1.76 \% ; \mathrm{Ca}=0.52 \% ; \mathrm{Mg}=0.22 \% ; \mathrm{S}=0.12 \%$; $\mathrm{B}=6.8 \mathrm{mg} \mathrm{kg}^{-1} ; \mathrm{Cu}=12.7 \mathrm{mg} \mathrm{kg}^{-1} ; \mathrm{Fe}=412 \mathrm{mg} \mathrm{kg}^{-1} ; \mathrm{Mn}=$ $39.5 \mathrm{mg} \mathrm{kg}^{-1} ; \mathrm{Zn}=30.3 \mathrm{mg} \mathrm{kg}^{-1}$; and $\mathrm{Na}=360 \mathrm{mg} \mathrm{kg}^{-1}$ ) and seed inoculation with Bradyrhizobium japonicum on common bean (Phaseolus vulgaris) southern blight, cultivated in a greenhouse, and also on the fluorescent Pseudomonas spp. native population. The addition of straw $\left(10 \mathrm{t} \mathrm{ha}^{-1}, 20 \mathrm{tha}^{-1}\right.$, and $\left.30 \mathrm{tha}^{-1}\right)$ reduced the severity of the disease, while the seed inoculation with Rhizobium did not. There was a significant increase of fluorescent Pseudomonas populations in soils with straw. These results indicate that the addition of pearl millet straw to soil can reduce the disease and favour the fluorescent Pseudomonas population growth.
\end{abstract}

KEY-WORDS: Sclerotium rolfsii; Pennisetum glaucum; Phaseolus vulgaris; fluorescent Pseudomonas spp.

\section{INTRODUÇÃO}

Sclerotium rolfsii é um fungo do solo e patógeno facultativo de uma ampla gama de plantas hospedeiras, registrado, pela primeira vez, em 1892, por Rolfs, em tomate (Solanum lycopersicum) (Punja 1985). A maioria das espécies de plantas a ele suscetíveis são dicotiledôneas, porém, existem diversas hospedeiras também entre as monocotiledôneas (Punja 1985, 1993). A forma sexuada de S. rolfsii é Athelia rolfsii, mas sua ocorrência natural é pouco frequente (Sarma \& Singh 2002). Contudo, quando ocorre, os basidiósporos podem, também,

\section{RESUMO}

Plantas como o milheto (Pennisetum glaucum) podem ser cultivadas para incorporação ou cobertura do solo. Tal prática favorece a melhoria das características químicas, físicas e biológicas do solo. Estes efeitos refletemse no controle de doenças, entre elas as causadas por Sclerotium rolfsii. Neste estudo, foi conduzida uma série de experimentos, em blocos ao acaso, para avaliar o efeito da adição de palha de milheto $(\mathrm{N}=0,8 \% ; \mathrm{P}=0,14 \% ; \mathrm{K}=1,76 \%$; $\mathrm{Ca}=0,52 \% ; \mathrm{Mg}=0,22 \% ; \mathrm{S}=0,12 \% ; \mathrm{B}=6,8 \mathrm{mg} \mathrm{kg}^{-1}$; $\mathrm{Cu}=12,7 \mathrm{mg} \mathrm{kg}^{-1} ; \mathrm{Fe}=412 \mathrm{mg} \mathrm{kg}^{-1} ; \mathrm{Mn}=39,5 \mathrm{mg} \mathrm{kg}^{-1}$; $\mathrm{Zn}=30,3 \mathrm{mg} \mathrm{kg}^{-1}$; e $\mathrm{Na}=360 \mathrm{mg} \mathrm{kg}^{-1}$ ) e da inoculação de sementes com Bradyrhizobium japonicum, sobre a podridão do colo em feijoeiro (Phaseolus vulgaris), cultivado em casade-vegetação, e sobre a população nativa de Pseudomonas spp. do grupo fluorescente. Com a adição de palha (10 t ha-1, $20 \mathrm{t} \mathrm{ha}^{-1}$ e $30 \mathrm{t} \mathrm{ha}^{-1}$ ), houve redução na severidade da doença, fato não observado em tratamentos com rizóbio. Ocorreu aumento da população de Pseudomonas fluorescente em solos com milheto. Os resultados indicam que a adição de palha de milheto ao solo pode reduzir a doença e favorecer a população de Pseudomonas fluorescente.

PALAVRAS-CHAVE: Sclerotium rolfsii; Pennisetum glaucum; Phaseolus vulgaris; Pseudomonas spp. fluorescente.

dar início a uma infecção primária (Punja \& Rahe 1992).

Em feijoeiro (Phaseolus vulgaris), os sintomas iniciam-se por lesões marrons sobre o colo, que avançam, produzindo escurecimento e podridão do caule, resultando em destruição do córtex e da raiz principal. Os sintomas reflexos ocorrem na parte aérea, na forma de amarelecimento das folhas baixeiras, seguindo em direção às folhas superiores. Em condições de alta umidade, ocorre crescimento micelial branco sobre o colo da planta. Sobre este micélio, é comum o aparecimento de escleródios marrons. 
Dentre as medidas de controle da doença, inclui-se o tratamento químico das sementes e solo, calagem, aplicação de resíduos orgânicos com elevada relação $\mathrm{C} / \mathrm{N}$, como palha de milho (Zea mays) e aveia (Avena sativa), e aração profunda (Punja 1985). $\mathrm{O}$ controle químico apresenta problemas quanto à eficiência, custo e impacto ao ambiente (Ghini et al. 1997). Poucos são os genótipos de feijoeiro com algum nível de resistência à doença (Chaves \& Costa 1999, Blum et al. 2002a), apesar de serem uma das formas de controle mais desejáveis.

A adição de resíduos ao solo é uma opção para o controle de doenças (Blum \& Rodríguez-Kábana 2004). Tal técnica tem demonstrado eficiência, como ocorreu em estudo onde se reduziu o tombamento (Phytophthora capsici) do pepino (Cucumis sativus), com a adição de cama de aviário e casca de pinus (Blum et al. 2002b). McIntyre et al. (2001) relataram a redução de nematóides fitoparasitas em bananeira, por meio da incorporação de leguminosas (Mucuna pruriens, Canavalia ensiforis e Tephrosia vogelii). A cobertura proporcionada por milheto (Pennisetum glaucum) diminui a incidência de doenças como o mofo-branco (Sclerotinia sclerotiorum) (Cassiolato 1998). Meyer (1996) relata redução no inóculo de Diaporthe phaseolorum f. sp. meridionalis (cancro da haste em soja), devido ao cultivo prévio de milheto. Em adição, Silva et al. (1997) informam que a palhada de milheto em semeadura direta resultou em maior velocidade de degradação de ovos do nematóide de cisto (Heterodera glycines) da soja (Glycine max). Segundo Garcia \& Silva (1996), isto se deve ao estímulo a antagonistas de ocorrência natural no solo. Muitos grupos de antagonistas podem ser favorecidos pela adição de resíduos vegetais ao solo, dentre eles o das Pseudomonas (P. putida e P. fluorescens) fluorescentes (Blum \& Lin 1991, Weller et al. 2002).

Escassas são as informações sobre a interação entre bactérias simbiontes fixadoras de nitrogênio e fitopatógenos. Os resultados obtidos não permitem concluir sobre os efeitos desta prática cultural, considerando-se que a prática da inoculação é relevante no cultivo de leguminosas, especialmente o feijoeiro (Hungria et al. 2001, 2003).

Dessa forma, foram objetivos deste trabalho verificar se a adição de palhada de milheto ao solo interfere na intensidade da podridão do colo em feijoeiro e sobre a população nativa de Pseudomonas fluorescentes e determinar se há efeito da inocu- lação das sementes com rizóbio, na ocorrência da doença.

\section{MATERIAL E MÉTODOS}

Foram utilizados três isolados de $S$. rolfsii, dois pertencentes à coleção micológica da Universidade de Brasília (UnB 46 e UnB 1114) e um terceiro isolado de hastes de soja (Glycine max) cultivada com base no Plano de Assentamento Dirigido do Distrito Federal (PAD-DF). No estudo envolvendo a inoculação com rizóbios, foi utilizado apenas o isolado UnB 1114.

Os isolados de $S$. rolfsii foram cultivados em placas de petri, contendo meio BDA(Batata Dextrose Agar) tradicional. Após a cobertura de toda a superfície da placa pelo micélio, cinco discos $(0,5 \mathrm{~cm}$ de diâmetro) foram transferidos para erlenmeyers (1 L), contendo $150 \mathrm{~g}$ de sementes de sorgo e $150 \mathrm{~mL}$ de água destilada, previamente autoclavada $\left(121^{\circ} \mathrm{C}, 20\right.$ minutos). Diariamente, os frascos foram agitados, visando a favorecer uma colonização mais rápida e homogênea do substrato.

Para a inoculação das plantas de feijão, foram pesados $5 \mathrm{~g}$ do substrato colonizado por $S$. rolfsii, que, então, foram acondicionados em copos plásticos de $50 \mathrm{~mL}$ e cobertos com filme plástico, até o momento da inoculação dos feijoeiros. Os experimentos foram conduzidos em blocos ao acaso, com quatro repetições de cinco plantas por vaso.

Para o estudo dos efeitos da adição de palhada sobre a podridão do colo, foi instalado experimento em casa-de-vegetação, utilizando-se vasos de plástico preto $(3 \mathrm{~L})$. Em todos os tratamentos, foi adicionada areia lavada, na proporção de $30 \%$ (2.300 g de solo + $700 \mathrm{~g}$ de areia). Foram utilizados seis tratamentos e um controle, com quatro repetições. O controle foi constituído apenas da mistura de solo e areia. Três tratamentos receberam doses equivalentes a $10 \mathrm{t} \mathrm{ha}^{-1}$ (80 kg ha ${ }^{-1}, 14 \mathrm{~kg} \mathrm{ha}^{-1}$ e $176 \mathrm{~kg} \mathrm{ha}^{-1}$ de N, P e K, respectivamente), $20 \mathrm{t} \mathrm{ha}^{-1}\left(160 \mathrm{~kg} \mathrm{ha}^{-1}, 28 \mathrm{~kg} \mathrm{ha}^{-1} \mathrm{e}\right.$ $352 \mathrm{~kg} \mathrm{ha}^{-1}$ de N, P e K, respectivamente) e $30 \mathrm{t} \mathrm{ha}^{-1}$ ( $240 \mathrm{~kg} \mathrm{ha}^{-1}, 42 \mathrm{~kg} \mathrm{ha}^{-1}$ e $528 \mathrm{~kg} \mathrm{ha}^{-1}$ de N, P e K, respectivamente) de palhada. Nos demais tratamentos, foram acrescentadas doses de nitrogênio, fósforo e potássio, em teores equivalentes $\left(10 \mathrm{tha}^{-1}\right.$, correspondendo a $80 \mathrm{~kg} \mathrm{ha}^{-1}, 14 \mathrm{~kg} \mathrm{ha}^{-1}$ e $176 \mathrm{~kg} \mathrm{ha}^{-1}$ de N, P e $\mathrm{K}$, respectivamente) aos apontados pela análise foliar do milheto utilizado. As fontes de N, P e K foram, respectivamente, ureia $(44 \% \mathrm{~N})$, superfosfato simples 
(18\% $\mathrm{P}_{2} \mathrm{O}_{5}$ solúvel em ácidos) e cloreto de potássio $\left(58 \% \mathrm{~K}_{2} \mathrm{O}\right)$. Os tratamentos foram aplicados 30 dias antes do primeiro plantio.

Neste experimento, utilizou-se solo (Latossolo Vermelho escuro) coletado na área Experimental de Biologia da Universidade de Brasília. O solo usado apresentou as seguintes características granulométricas: $200 \mathrm{~g} \mathrm{~kg}^{-1}$ de areia, $200 \mathrm{~g} \mathrm{~kg}^{-1}$ de silte e $600 \mathrm{~g} \mathrm{~kg}^{-1}$ de argila. A análise química do solo apresentou $\mathrm{pH}\left(\mathrm{H}_{2} \mathrm{O}\right)=5,7$; Matéria orgânica $=$ $21,8 \mathrm{~g} \mathrm{~kg}^{-1} ; \mathrm{P}=0,5 \mathrm{mg} \mathrm{dm}{ }^{-3} ; \mathrm{K}=0,22 \mathrm{cmol}_{\mathrm{c}} \mathrm{dm}^{-3}$; $\mathrm{Ca}=1,6 \mathrm{cmol}_{\mathrm{c}} \mathrm{dm}^{-3} ; \mathrm{Mg}=0,5 \mathrm{cmol}_{\mathrm{c}} \mathrm{dm}^{-3}$; acidez total $(\mathrm{H}+\mathrm{A})=5 \mathrm{cmol}_{\mathrm{c}} \mathrm{dm}^{-3}$; soma de bases $=$ $2,4 \mathrm{cmol}_{\mathrm{c}} \mathrm{dm}^{-3} ; \mathrm{CTC}=7,4 \mathrm{cmol}_{\mathrm{c}} \mathrm{dm}^{-3}$; saturação por bases $=32 \% ; \mathrm{B}=0,41 \mathrm{mg} \mathrm{dm}^{-3} ; \mathrm{Cu}=0,95 \mathrm{mg} \mathrm{dm}^{-3}$; $\mathrm{Fe}=28,3 \mathrm{mg} \mathrm{dm}^{-3} ; \mathrm{Mn}=5,66 \mathrm{mg} \mathrm{dm}^{-3} ; \mathrm{Zn}=$ $1,17 \mathrm{mg} \mathrm{dm}^{-3}$; e $\mathrm{S}=9,9 \mathrm{mg} \mathrm{dm}^{-3}$.

Para estudo da influência da inoculação das sementes com rizóbio, foi instalado um teste com seis tratamentos e uma testemunha, sendo cada tratamento com quatro repetições de cinco plantas por vaso. Foram utilizados vasos contendo dose de $20 \mathrm{t} \mathrm{ha}^{-1}$ de milheto, quantidades equivalentes de N, P e K e controles. Para os três casos, houve um tratamento sem inoculação com rizóbios e um equivalente onde as sementes foram inoculadas com uma mistura das estirpes de rizóbio CPAC 41 e CPAC 444 em turfa.

Neste experimento, foi utilizado solo sob Cerrado nativo, nunca antes cultivado. Este solo foi coletado na Embrapa Cerrados (Centro Nacional de Pesquisa Agropecuária dos Cerrados, CPAC, Planaltina, DF). Quanto à granulometria, o solo utilizado apresentou $300 \mathrm{~g} \mathrm{~kg}^{-1}$ de areia, $150 \mathrm{~g} \mathrm{~kg}^{-1}$ de silte e $550 \mathrm{~g} \mathrm{~kg}^{-1}$ de argila. A análise química do solo apresentou $\mathrm{pH}\left(\mathrm{H}_{2} \mathrm{O}\right)=4,5 ; \mathrm{MO}=24,8 \mathrm{~g} \mathrm{~kg}^{-1} ; \mathrm{P}=0,5 \mathrm{mg} \mathrm{dm}^{-3}$; $\mathrm{K}=0,08 \mathrm{cmol}_{\mathrm{c}} \mathrm{dm}^{-3} ; \mathrm{Ca}=0,2 \mathrm{cmol}_{\mathrm{c}} \mathrm{dm}^{-3}$; $\mathrm{Mg}=0,1 \mathrm{cmol}_{\mathrm{c}} \mathrm{dm}^{-3}$; acidez total $(\mathrm{H}+\mathrm{A})=$ $7,81 \mathrm{cmol}_{\mathrm{c}} \mathrm{dm}^{-3}$; soma de bases $=0,39 \mathrm{cmol}_{\mathrm{c}} \mathrm{dm}^{-3}$; $\mathrm{CTC}=8,2 \mathrm{cmol}_{\mathrm{c}} \mathrm{dm}^{-3}$; saturação por bases $=$ $5 \% ; \mathrm{B}=0,04 \mathrm{mg} \mathrm{dm}^{-3} ; \mathrm{Cu}=3,16 \mathrm{mg} \mathrm{dm}^{-3}$; $\mathrm{Fe}=95,4 \mathrm{mg} \mathrm{dm}^{-3} ; \mathrm{Mn}=1,58 \mathrm{mg} \mathrm{dm}^{-3} ; \mathrm{Zn}=$ $0,56 \mathrm{mg} \mathrm{dm}^{-3}$; e $\mathrm{S}=2,3 \mathrm{mg} \mathrm{dm}^{-3}$.

A palhada usada foi proveniente de cultivo em campo da Embrapa Cerrados. Antes da incorporação, o material foi cortado em frações de até $5 \mathrm{~cm}$. O material apresentou a seguinte composição: $\mathrm{N}=0,8 \%$; $\mathrm{P}=0,14 \% ; \mathrm{K}=1,76 \% ; \mathrm{Ca}=0,52 \% ; \mathrm{Mg}=0,22 \%$; $\mathrm{S}=0,12 \% ; \mathrm{B}=6,8 \mathrm{mg} \mathrm{kg}^{-1} ; \mathrm{Cu}=12,7 \mathrm{mg} \mathrm{kg}^{-1} ; \mathrm{Fe}=$
$412 \mathrm{mg} \mathrm{kg}^{-1} ; \mathrm{Mn}=39,5 \mathrm{mg} \mathrm{kg}^{-1} ; \mathrm{Zn}=30,3 \mathrm{mg} \mathrm{kg}^{-1}$; e Na $=360 \mathrm{mg} \mathrm{kg}^{-1}$.

Foram realizadas coletas de solo ao final de cada trinta dias. Em cada época de amostragem, foram coletados $100 \mathrm{~g}$ de solo de cada tratamento. As amostras foram mantidas em câmara fria, até o processamento. Inicialmente, $10 \mathrm{~g}$ de solo foram diluídos em $90 \mathrm{~mL}$ de água destilada e autoclavada, em um erlenmeyer de $125 \mathrm{~mL}$. Esta solução foi agitada por 10 minutos, a $200 \mathrm{rpm}$ e $25^{\circ} \mathrm{C}$. Em seguida, uma alíquota de $1 \mathrm{~mL}$ desta solução foi transferida para um tubo de ensaio contendo $9 \mathrm{~mL}$ de água destilada autoclavada. Realizou-se diluição seriada até $10^{-6} \mathrm{e}$, em seguida, o plaqueamento, em meio King B modificado (20 g de peptona; $2,5 \mathrm{~g}$ de $\mathrm{K}_{2} \mathrm{HPO}_{4} ; 6 \mathrm{~g}$ de $\mathrm{MgSO}_{4} .7 \mathrm{H}_{2} \mathrm{O} ; 15 \mathrm{~mL}$ de glicerol; $15 \mathrm{~g}$ de Agar; 0,05 g de carbendazin; e $1 \mathrm{~L}$ de água destilada). Após dois dias, realizou-se a contagem das colônias de bactérias fluorescentes, em câmara com luz ultravioleta. Os resultados das contagens foram ajustados de acordo com a umidade das amostras e transformados para log ufc $\mathrm{g}^{-1}$ (unidades formadoras de colônias) de solo seco. Após esta transformação, os dados foram submetidos a análise de variância.

Nos experimentos, foram utilizadas sementes de feijão fiscalizadas, cultivar Pérola, safra 2002/2003. Em cada vaso, foram mantidas cinco plantas, sendo a inoculação realizada após quatro dias da germinação, incorporando-se o inóculo, nos $2 \mathrm{~cm}$ superficiais do solo.

As plantas foram avaliadas aos 10, 20 e 30 dias após a germinação. Avaliou-se a incidência, severidade e número de plantas mortas. Para a avaliação, utilizou-se a seguinte escala de notas: (0) Plantas livres da doença; (1) Crescimento micelial próximo ao colo; (2) Crescimento micelial próximo ao colo e início de lesão; (3) Lesão no colo; (4) Lesão e murcha; (5) Murcha severa; e (6) Planta morta.

Aos 30 dias, as plantas foram retiradas e procedeu-se a nova semeadura. Em cada vaso, foram realizados quatro plantios consecutivos. Também, foram realizadas a pesagem da matéria fresca da parte aérea e sistema radicular de cada tratamento. A análise estatística foi realizada com as médias dos quatro plantios mensais consecutivos. Os dados foram submetidos a análise de variância, com repetição de medidas, e suas médias comparadas por meio do teste Tukey ( $\leq 5 \%$ ), utilizando-se o programa SigmaStat 2.0. 


\section{RESULTADOS E DISCUSSÃO}

Nas três avaliações realizadas aos 10, 20 e 30 dias, observou-se menor severidade da doença, nos três tratamentos envolvendo a adição de palha de milheto, em relação aos demais e ao controle, para os três isolados estudados (Figura 1A). As doses recíprocas e equivalentes àquelas de milheto em adubo químico não reduziram a severidade da doença.

Diversos trabalhos têm evidenciado efeito positivo da adição de resíduos orgânicos ao solo, no controle de doenças. Kubiak (2003) observou que, quando as condições meteorológicas são favoráveis ao patógeno (Colletotrichum gossypii var. cephalosporioides Costa) e a cultivar é suscetível, a presença da palha de milheto sobre a superfície do solo desfavorece o crescimento da doença ramulose em algodoeiro. Ferraz et al. (2003), estudando a viabilidade de Sclerotinia sclerotiorum, após solarização do solo, na presença de cobertura morta, observaram maior eficiência da solarização do solo na presença de palha, conferida pela redução da viabilidade dos esclerócios.

Resíduos orgânicos podem, por meio de transformações bioquímicas, ser mineralizados e convertidos em compostos orgânicos. Assim, observam-se efeitos benéficos nas características químicas, físicas e biológicas, contribuindo para a indução de supressividade no solo (Hoitinik \& Fahy 1986, RodríguezKábana \& Calvet 1994, Weller et al. 2002). De acordo com Almeida (1986), materiais com alta relação C/N, na maioria constituída de lignina, como a palha de milho, podem, no processo de decomposição, ter a relação $\mathrm{C} / \mathrm{N}$ aumentada. Posteriormente, esta relação tende a decrescer, chegando a uma situação estável. Este processo é lento e leva à formação de compostos alelopáticos, de liberação gradativa.

Ao contrário dos resultados obtidos por Hoynes et al. (2002), em estudo envolvendo o manejo integrado de $S$. rolfsii em feijoeiro, não foi observado efeito da fertilização do solo. Tal fato pode estar relacionado às doses utilizadas, que podem ser consideradas baixas (Figura 1A). Além disso, sabe-se que os efeitos da adição de resíduos orgânicos são mais amplos que a simples nutrição da planta hospedeira. Assim, a redução de severidade observada, quando se usou palhada de milheto, pode estar relacionada à degradação da matéria orgânica, com a liberação de substâncias que podem tanto apresentar características favoráveis ao desenvolvimento de antagonistas como inibitórias ao patógeno.
Ainda, quanto à severidade da doença, nas três avaliações, observou-se efeito do isolado de $S$. rolfsii (dados não apresentados). Não houve diferença significativa entre o isolado PAD-DF e o isolado UnB 46. Os isolados UnB 1114 e UnB 46 também não apresentaram diferenças significativas entre si (dados não apresentados).
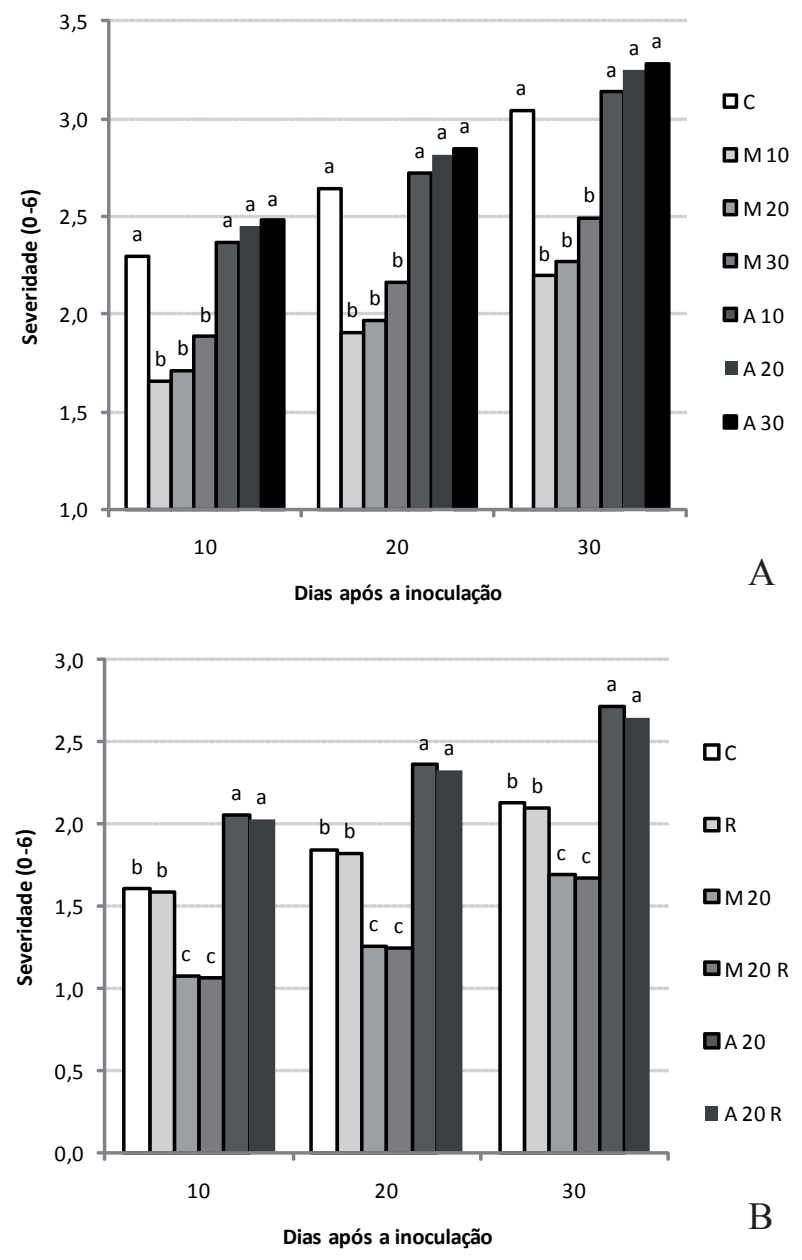

Figura 1. Efeito da incorporação ao solo de milheto e adubo químico na severidade da doença causada por Sclerotium rolfsii em feijoeiro. (A) Severidade da doença (0-6), em função do tratamento $(\mathrm{C}=$ controle; $\mathrm{M} 10=$ milheto $10 \mathrm{t} \mathrm{ha}^{-1} ; \mathrm{M} 20=$ milheto $20 \mathrm{t} \mathrm{ha}^{-1}$; $\mathrm{M} 30=$ milheto $30 \mathrm{t} \mathrm{ha}^{-1}$; A10 = adubo químico $10 \mathrm{tha}^{-1}$; A20 = adubo químico $20 \mathrm{tha}^{-1}$; A30 = adubo químico $\left.30 \mathrm{t} \mathrm{ha}^{-1}\right)$. (B) Severidade da doença (0-6), em função do tratamento $(\mathrm{C}=$ controle; $\mathrm{R}=$ rizóbio; $\mathrm{M} 20=$ milheto $20 \mathrm{t} \mathrm{ha}^{-1}$; M20R = milheto $20 \mathrm{t} \mathrm{ha}^{-1} \mathrm{e}$ rizóbio; A20 = adubo químico $20 \mathrm{t} \mathrm{ha}^{-1}$; A20R = adubo químico $20 \mathrm{t} \mathrm{ha}^{-1}$ e rizóbio), aos 10, 20 e 30 dias após a inoculação do patógeno. Barras de valores com a mesma letra não diferiram significativamente entre si (Tukey, $5 \%$ ). Os resultados se referem à média de quatro plantios. 
Houve uma tendência quadrática significativa de aumento da matéria verde da parte aérea das plantas, com o aumento da quantidade de milheto (Figura 2A), com ótimo próximo a $20 \mathrm{t} \mathrm{ha}^{-1}$, tendência, esta, possivelmente relacionada, em parte, à menor intensidade de doença nos tratamento com milheto. Quanto à matéria fresca das raízes, houve tendência quadrática significativa de aumento da quantidade de milheto (Figura 2B), com ótimo próximo a $15 \mathrm{t} \mathrm{ha}^{-1}$. Não foram detectadas tendências significativas em solo com adubação química, quanto à matéria fresca de raízes e parte aérea (dados não apresentados).

Foi observada menor severidade nos tratamentos com adição de palhada de milheto, em relação aos demais tratamentos. No entanto, considerando-se os tratamentos com a inoculação das sementes com rizóbio, não foram detectadas diferenças significativas entre os tratamentos de solo. Não houve, assim, diferença na severidade da doença, no tratamento com $20 \mathrm{t} \mathrm{ha}^{-1}$, com ou sem inoculação das sementes com rizóbio. O mesmo pode ser observado nos controles e nos tratamentos envolvendo adubação química (Figura 2C).

Em relação à contagem de bactérias fluorescentes (Pseudomonas do grupo fluorescente), observaram-se maiores valores nos tratamentos com adição de $20 \mathrm{t} \mathrm{ha}^{-1}$ e $30 \mathrm{t} \mathrm{ha}^{-1}$ de milheto ao solo, em relação a todos os demais tratamentos, com tendência quadrática significativa (Figura 3A). Entre os tratamentos com adição de adubos químicos, não houve diferença, inclusive em relação ao controle. Houve tendência significativa de redução da doença, com o aumento da população estimada de Pseudomonas

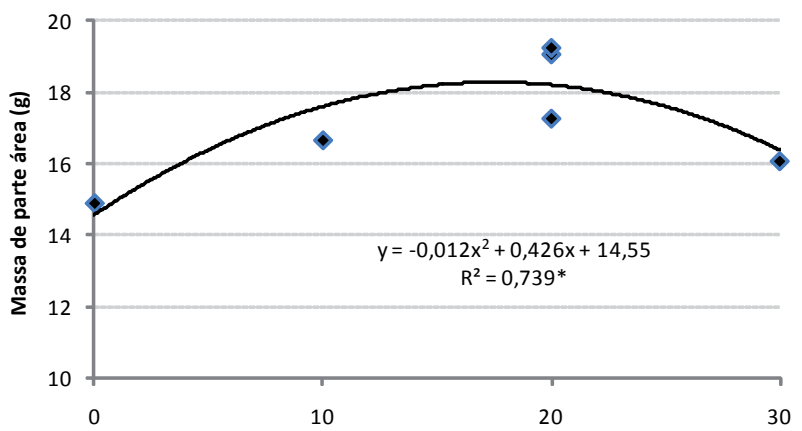

A

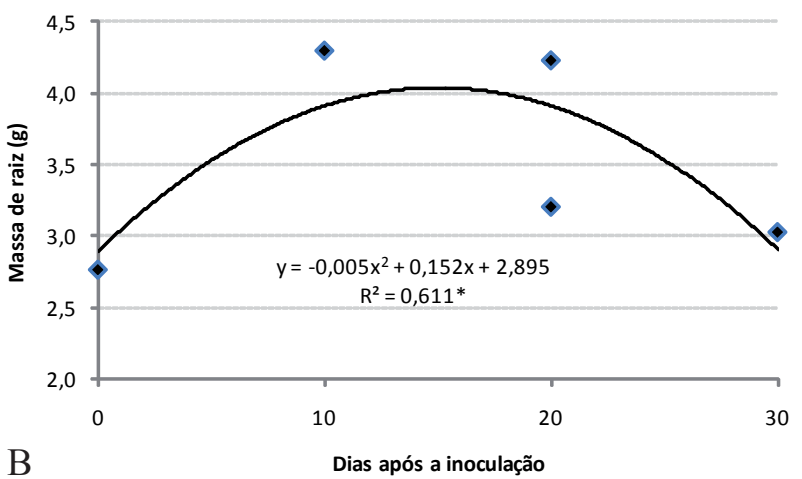

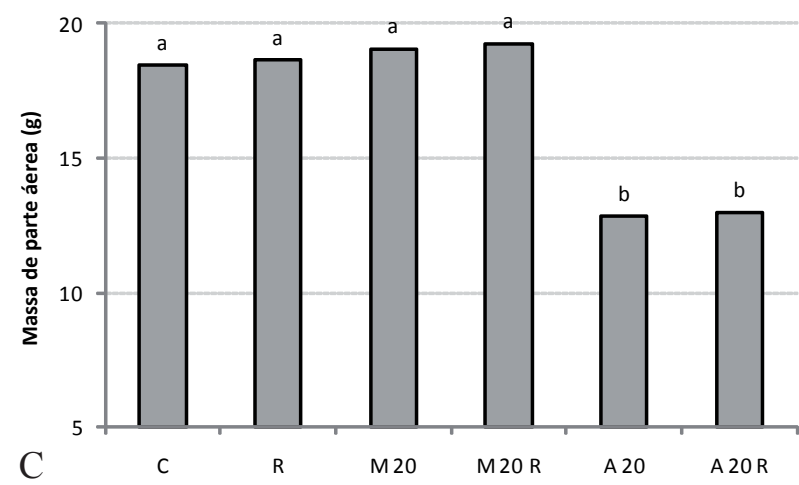

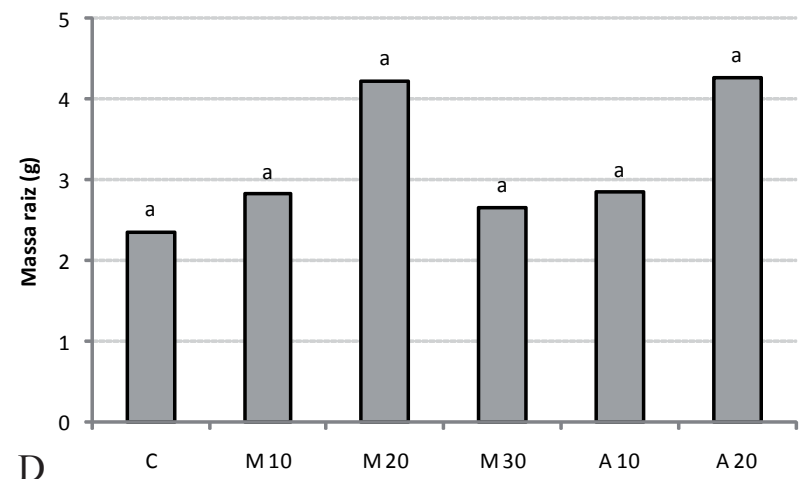

Figura 2. Efeito da incorporação ao solo de milheto e adubo químico na massa vegetal fresca em feijoeiro. (A) Matéria vegetal fresca da parte aérea de plântulas de feijoeiro, aos 30 dias AIP, em função da dose de produto incorporado ao solo. (B) Matéria vegetal fresca das raízes de plântulas de feijoeiro, aos 30 dias após a inoculação do patógeno, em função da dose de produto incorporado ao solo. (C) Matéria vegetal fresca da parte aérea de plântulas de feijoeiro, aos 30 dias após a inoculação do patógeno, em função do produto incorporado ao solo $\left(\mathrm{C}=\right.$ controle; $\mathrm{R}=$ rizóbio; $\mathrm{M} 20=$ milheto 20 t ha ${ }^{-1} ; \mathrm{M} 20 \mathrm{R}=$ milheto 20 t ha $^{-1}$ e rizóbio; A20 = adubo químico 20 t ha $^{-1}\left(160 \mathrm{~kg} \mathrm{ha}^{-1}, 28 \mathrm{~kg} \mathrm{ha}^{-1}\right.$ e $352 \mathrm{~kg} \mathrm{ha}^{-1} \mathrm{de} \mathrm{N}$, P e K, respectivamente); e $\mathrm{A} 20 \mathrm{R}$ = adubo químico $20 \mathrm{t} \mathrm{ha}^{-1}$ e rizóbio). (D) Matéria vegetal fresca das raízes de plântulas de feijoeiro, aos 30 dias após a inoculação do patógeno. (C e D) Barras de valores com a mesma letra não diferiram, significativamente, entre si (Tukey, 5\%). (A e B) Equação com coeficiente de regressão significativo, a 5\% (*) de probabilidade de erro. Os resultados se referem à média de quatro plantios. 

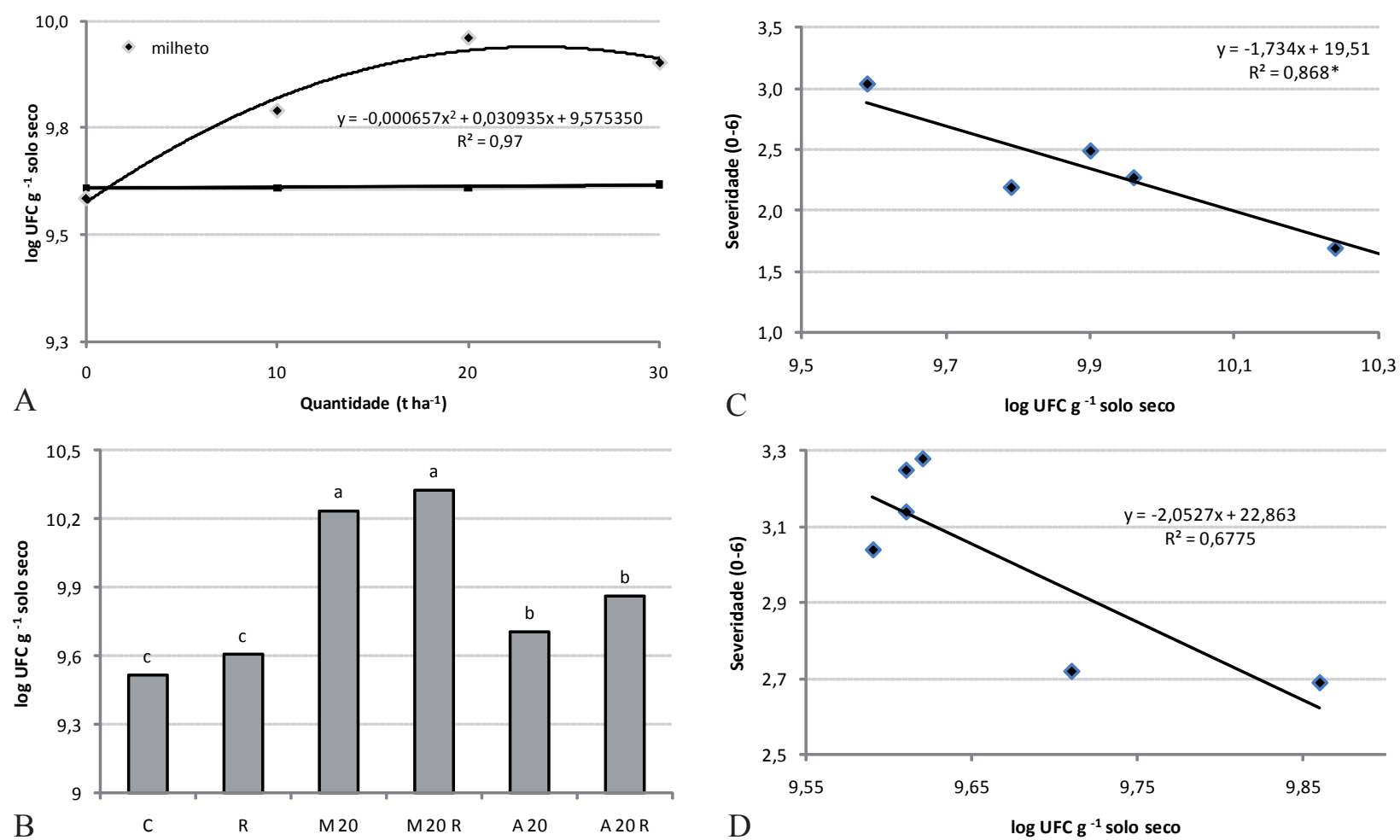

Figura 3. Efeito da incorporação ao solo de palha de milheto e Bradyrhizobium japonicum, na população de Pseudomonas do grupo fluorescente, aos 30 dias após a inoculação do patógeno (AIP). (A) Estimativa da população do solo de Pseudomonas do grupo fluorescente, aos 30 dias AIP, em função da dose de produto incorporado ao solo. Equação com coeficiente de regressão significativo a 5\% de probabilidade de erro. (B) Estimativa da população do solo de Pseudomonas do grupo fluorescente, aos 30 dias AIP, em função do produto incorporado ao solo $\left(\mathrm{C}=\right.$ controle; $\mathrm{R}=$ rizóbio; $\mathrm{M} 20=$ milheto 20 t ha ${ }^{-1} ; \mathrm{M} 20 \mathrm{R}=$ milheto $20 \mathrm{t} \mathrm{ha}^{-1}$ e rizóbio; A20 = adubo químico $20 \mathrm{tha}^{-1}$; A20R = adubo químico $20 \mathrm{t} \mathrm{ha}^{-1}$ e rizóbio). (C) Severidade da doença, em função da população estimada de Pseudomonas fluorescente, em solo com palha de milheto. (D) Severidade da doença, em função da população estimada de Pseudomonas fluorescente, em solo com adubo químico. (A e B) Barras de valores com a mesma letra não diferiram, significativamente, entre si (Tukey, 5\%). (C e D) Equação com coeficiente de regressão significativo a $5 \%\left(^{*}\right)$ de probabilidade de erro. Os resultados se referem à média de quatro plantios.

do grupo fluorescente, em solo com palha de milheto (Figura 3C). Embora, em solo com adubo químico, tenha havido tal tendência de redução da doença, com o aumento da população estimada de Pseudomonas do grupo fluorescente (Figura 3D), a mesma não foi significativa.

As espécies Pseudomonas fluorescens e $P$. putida produzem vários antibióticos, $\mathrm{HCN}$ e sideróforos, como mecanismos maiores envolvidos no biocontrole (O'Sullivan \& O'Gara 1992). Assim sendo, um incentivo ao aumento da população natural destas bactérias no solo deve ter papel relevante na supressão de S. rolfsii (Manjula et al. 2004).

Estudos anteriores relataram que $P$. putida reduziu a murcha vascular do algodão (Gossypium hirsutum), causada por F. oxyporum f.sp. vasinfectum (Chen et al. 1995), e que Pseudomonas fluorescens e $P$. putida estavam associadas (Sivasithamparam et al. 1979) à supressão de Gaeumannomyces graminis var. tritici, causador do mal-do-pé, em trigo (Triticum aestivum).

Os mecanismos envolvidos no controle biológico de fitopatógenos podem variar de acordo com as espécies das bactérias associadas ao controle. Hiperparasitismo, antibiose, produção de sideróforos, crescimento de plantas, indução de resistência e competição por nutrientes e sítios de colonização podem estar envolvidos na supressão da população dos patógenos e da intensidade da doença (Kloepper \& Schroth 1981).

A atividade e a população dos micro-organismos do solo são alteradas pela adição de matéria orgânica ao solo. Estudos têm mostrado que a adição de, por exemplo, casca de pinus (Pinus spp.), mucuna (Mucuna spp.) e pueraria (Pueraria spp.), entre outros, pode influenciar no aumento da população de 
determinados antagonistas (Bacillus megaterium, Enterobacter aerogenes, P. fluorescens, P. putida, Penicillium spp., Trichoderma spp., etc.) nativos do solo (Blum \& Rodríguez-Kabana 2006). Há relatos de correlação positiva entre a quantidade de matéria orgânica adicionada ao solo e a atividade enzimática, indicando, consequentemente, aumento na população e atividade de micro-organismos no solo (Weller et al. 2002, Blum \& Rodríguez-Kábana 2004).

A adição de palha de milheto ao solo favoreceu a redução da podridão do colo. Assim, seria interessante a utilização de palhada como prática alternativa aos agrotóxicos, para o controle desta doença.

\section{CONCLUSÃO}

A adição de palha de milheto ao solo reduziu a podridão do colo (Sclerotium rolfsii) em feijoeiro e estimulou o aumento da população natural de Pseudomonas do grupo fluorescente.

\section{AGRADECIMENTOS}

Ao Conselho Nacional de Desenvolvimento Científico e Tecnológico (CNPq) e à Coordenação de Aperfeiçoamento de Pessoal de Nível Superior (Capes), pelo financiamento parcial do estudo.

\section{REFERÊNCIAS}

ALMEIDA, F. S. Influência da cobertura morta do plantio direto na biologia do solo. In: FANCELLI, A. L.; TORRADO, P. V.; MACHADO, J. (Eds.). Atualização em plantio direto. Piracicaba: Fundação Cargill, 1986. p. 103-144.

BLUM, L. E. B.; LIN, M. T. Potencial de Trichoderma e Pseudomonas fluorescente para o controle do tombamento de mudas de eucalipto causado por Cylindrocladium spp. Fitopatologia Brasileira, Brasília, DF, v. 16, n. 1, p. 7174, 1991.

BLUM, L. E. B.; RODRÍGUEZ-KÁBANA, R. Effect of organic amendments on sclerotial germination, mycelial growth, and Sclerotium rolfssi - induced diseases. Fitopatologia Brasileira, Brasília, DF, v. 29, n. 1, p. 6674, 2004.

BLUM, L. E. B.; RODRÍGUEZ-KÁBANA, R. Powders of kudzu, velvetbean, and pine bark added to soil increase microbial population and reduce southern blight of soybean. Fitopatologia Brasileira, Brasília, DF, v. 31, n. 6, p. 551-556, 2006.
BLUM, L. E. B. et al. Reação de genótipos de Phaseolus vulgaris à podridão do colo a ao oídio. Fitopatologia Brasileira, Brasília, DF, v. 28, n. 1, p. 96-100, 2002a.

BLUM, L. E. B. et al. Manejo do tombamento em pepino pela adição ao solo de cama de aviário e casca de pinus. Revista de Ciências Agroveterinárias, Lages, v. 1, n. 1, p. 33-40, 2002 b.

CASSIOLATO, A. M. R. Ecologia de fungos fitopatogênicos formadores de esclerócios. In: MELO, I. S. de; AZEVEDO, J. L. de (Eds.). Ecologia microbiana. Jaguariúna: Embrapa, 1998. p. 139-165.

CHAVES, K. C.; COSTA, J. L. S. Influência do método de inoculação e da quantidade de inóculo de Sclerotium rolfsii na severidade de podridão do colo do feijoeiro. Summa Phytopathologica, Jaboticabal, v. 25, n. 4, p. 298302, 1999.

CHEN, C. et al. Biological control of fusarium wilt on cotton by use of endophytic bacteria. Biological Control, Amsterdam, v. 5, n. 1, p. 83-91, 1995.

FERRAZ, L. C. L. et al. Viabilidade de Sclerotinia sclerotiorum após a solarização do solo na presença de cobertura morta. Fitopatologia Brasileira, Brasília, DF, v. 28, n. 1, p. 17-26, 2003.

GARCIA, A.; SILVA, J. F. V. Nematóide de cisto da soja. Revista Plantio Direto, Passo Fundo, v. 34, n. 1, p. 21-22, 1996.

GHINI, R.; BETTIOL, W.; CALDARI JR., P. Solarização do solo para o controle de Sclerotium rolfsii em feijoeiro. Summa Phytopathologica, Jaboticabal, v. 23, n. 2, p. 143 145, 1997.

HOITINIK, H. A. J.; FAHY, P. C. Basis for the control of soil-borne plant pathogens with composts. Annual Review of Phytopathology, Palo Alto, v. 24, n. 1, p. 93114, 1986.

HOYNES, C. D. et al. Biological control agents in combination with fertilization or fumigation to reduce sclerotial viability of Sclerotium rolfsii and disease of snap beans in the greenhouse. Journal of Phytopathology, Berlin, v. 147, n. 3, p. 175-182, 2002.

HUNGRIA, M.; CAMPO, R. J.; MENDES, I. C. Benefits of inoculation of the common bean (Phaseolus vulgaris) crop with efficient and competitive Rhizobium tropici strains. Biology and Fertility of Soils, Berlin, v. 39, n. 2, p. 88-93, 2003.

HUNGRIA, M. et al. Symbiotic effectiveness of fastgrowing rhizobial strains isolated from soybean nodules in Brazil. Biology and Fertility of Soils, Berlin, v. 33, n. 5, p. 387-394, 2001. 
KLOEPPER, J. W.; SCHROTH, M. N. Relationship of in vitro antibiosis of plant growth-promoting rhizobacteria to plant growth and the displacement of root microflora. Phytopathology, St. Paul, v. 71, n. 10, p. 1020-1024, 1981.

KUBIAK, D. M. Influência da palhada de milheto na ocorrência de ramulose (Colletotrichum gossypii var. cephalosporioides Costa) no algodoeiro. 2003. $68 \mathrm{f}$. Dissertação (Mestrado em Fitotecnia)-Escola Superior de Agricultura "Luiz de Queiroz", Universidade de São Paulo, Piracicaba, 2003.

MANJULA, K. et al. Combined application of Pseudomonas fluorescens and Trichoderma viride has an improved biocontrol activity against stem rot in groundnut. The Plant Pathology Journal, Faisalabad, v. 20, n. 1, p. 7580, 2004.

McINTYRE, B. D. et al. Effects of legume intercrops on soil-borne pests, biomass, nutrients and soil water in banana. Biology and Fertility of Soils, Heidelberg, v. 34, n. 5, p. 342-348, 2001.

MEYER, M. C. Efeito de sistemas de semeadura, adubação potássica em cobertura e tratamentos químicos sobre a incidência de doenças fúngicas da soja. In: REUNIÃO DE PESQUISA DA SOJA DA REGIÃO CENTRAL, 18., 1996, Uberlândia. Anais... Uberlândia: UFU, 1996. p. 304-305.

O'SULLIVAN, D. J.; O'GARA, F. Traits of fluorescent Pseudomonas spp. involved in suppression of plant root pathogens. Microbiology and Molecular Microbiology Reviews, Madison, v. 56, n. 4, p. 662-676, 1992.

PUNJA, Z. K. Ecology and infection behavior of Sclerotium rolfsii Sacc. In: LYDA, S. D.; KENERLEY, C. M. Biology of sclerotial-forming fungi. Texas: The Texas Agricultural Experiment Station, 1993. p. 131-145.
PUNJA, Z. K. The biology, ecology, and control of Sclerotium rolfsii. Annual Review of Phytopathology, Palo Alto, n. 23, p. 97-127, 1985.

PUNJA, Z. K.; RAHE, J. E. Sclerotium. In: SINGLETON, L. L.; MIHAIL, J. D.; RUSH, C. M. Methods for research on soilborne phytopathogenic fungi. St. Paul: Minnesota APS Press, 1992. p. 166-170.

RODRÍGUEZ-KÁBANA, R.; CALVET, C. Capacidad del suelo para controlar enfermedades de origen edafico. Fitopatologia Brasileira, Brasília, DF, v. 19, n. 2, p. 129138, 1994.

SARMA, B. K.; SINGH, U. P. Variability in Indian isolates of Sclerotium rolfsii. Mycologia, Stanford, v. 94, n. 6, p. 1051-1058, 2002.

SILVA, J. F. V. et al. Dinâmicas populacionais do nematóide de cisto da soja Heterodera glycines e semeadura direta e convencional. In: REUNIÃO DE PESQUISA DE SOJA DA REGIÃO CENTRAL DO BRASIL, 19., 1997, Jaboticabal. Anais... Londrina: Embrapa-CNPSo, 1997. p. 201.

SIVASITHAMPARAM, K.; PARKER, C. A.; EDWARDS, C. S. Bacterial antagonists to the take-all fungus and fluorescent pseudomonads in the rhizosphere of wheat. Soil Biology \& Biochemistry, Amsterdam, v. 11, n. 2, p. 161-165, 1979.

WELLER, D. M. et al. Microbial populations responsible for specific soil suppressiveness to plant pathogens. Annual Review of Phytopathology, Palo Alto, n. 40, p. 309-347, 2002. 